\section{BMJ Open Respiratory Research}

\title{
Integrating patients with chronic respiratory disease and heart failure into a combined breathlessness rehabilitation programme: a service redesign and pilot evaluation
}

\author{
Emma Chaplin (D) , ${ }^{1}$ Sarah Ward, ${ }^{1}$ Enya Daynes, ${ }^{1,2}$ Claire LA Bourne, ${ }^{3}$ \\ Amy Stenson, ${ }^{1}$ Amye Watt, ${ }^{1}$ Nikki Gardiner, ${ }^{1}$ Linzy Houchen-Wolloff, ${ }^{1,2}$ \\ Sally J Singh ${ }^{1,2}$
}

To cite: Chaplin E, Ward S, Daynes E, et al. Integrating patients with chronic respiratory disease and heart failure into a combined breathlessness rehabilitation programme: a service redesign and pilot evaluation. BMJ Open Resp Res 2021;8:e000978. doi:10.1136/ bmjresp-2021-000978

- Additional supplemental material is published online only. To view, please visit the journal online (http://dx.doi. org/10.1136/bmjresp-2021000978).

Received 5 May 2021 Accepted 29 October 2021

D) Check for updates

\section{(c) Author(s) (or their} employer(s)) 2021. Re-use permitted under CC BY-NC. No commercial re-use. See rights and permissions. Published by BMJ.

For numbered affiliations see end of article.

Correspondence to Dr Emma Chaplin; emma.chaplin@uhl-tr.nhs.uk

\section{ABSTRACT}

Introduction The successful integration of patients with chronic heart failure (CHF) into a traditional pulmonary rehabilitation (PR) programme has previously been reported. Our aim was to reconfigure both our cardiac rehabilitation (CR) and PR services to enable us to deliver a symptom-based programme - breathlessness rehabilitation (BR), for patients with a primary symptom of breathlessness irrespective of the index diagnosis, or comorbid disease.

Methods After a service redesign process, patients attended a two times per week, group-based, tailored exercise and education programme for 6 weeks, delivered by CR and PR staff. The classes included both aerobic and resistance exercises and an overarching generic education programme alongside disease-specific components. Home programmes were reviewed at each session to facilitate progress and influence changes in exercise behaviour beyond the supervised programme. Generic clinical outcome measures were performed pre and post BR.

Staff focus groups were conducted to identify barriers and facilitators and explore staff perceptions.

Results 272 patients ( $n=193$ chronic respiratory disease (CRD) and $n=79$ CHF) were assessed and enrolled into BR (153 men, mean (SD) age 68.8 (12.7) years, body mass index 28.8 (7.3), Medical Research Council 3 (IQR 2-4), New York Heart Association 2 (IQR 2-3)). 164 patients completed the programme. Statistically significant improvements were seen in both exercise capacity (incremental shuttle walking test: mean change $47.4 \mathrm{~m}$; endurance shuttle walking test: mean change $310.7 \mathrm{~s}$ ) and quadriceps strength (quadriceps maximal voluntary contraction: mean change $3.7 \mathrm{~kg})(\mathrm{p} \leq 0.0001)$ alongside a statistically significant reduction in dyspnoea (chronic respiratory questionnaire/chronic heart questionnaire - self reported - dyspnoea: mean change 0.4 ) and anxiety and depression scores (Hospital Anxiety and Depression Scale (HADS) - anxiety: -1.6; HADS - depression: -1.3) ( $p \leq 0.0001)$. Qualitative staff focus groups identified three subthemes: collaboration and integration, service quality and future challenges.

Discussion Overall the service redesign indicates the feasibility for staff and individuals with CRD and CHF to integrate into a breathlessness programme. Early data

\section{Key messages}

Can patients benefit from an integrated rehabilitation programme treating the primary symptom of breathlessness rather than being disease specific?

Service development of a breathlessness rehabilitation is feasible and clinically effective for patients with pulmonary and cardiac disease and is acceptable to healthcare professionals.

- Consensus is growing for the provision of breathlessness rehabilitation and this model may be feasible to grow with the provision of generic rehabilitation to other chronic conditions whose core complaint is breathlessness. This article describes our service reconfiguration.

suggests clinical effectiveness. Given the significance of comorbid disease it is an approach that warrants further consideration.

\section{INTRODUCTION}

Breathlessness, of which there are a number of causes, is one of the most common reasons for people presenting to emergency departments, with numbers increasing steadily each year. ${ }^{12}$ Individuals suffering from breathlessness typically lead sedentary lifestyles, falling into a vicious cycle of physical inactivity, deconditioning and severe breathlessness on exertion. Exercise intolerance can be a result from limb and respiratory muscle alterations caused by hypoxia, systemic inflammation and disuse. ${ }^{3}$ The National Institute for Health and Care Excellence $^{45}$ recommends rehabilitation for individuals with chronic obstructive pulmonary disease (COPD) and chronic heart failure (CHF), comprising of an individually tailored 
exercise regime, multidisciplinary education, support and self-management as an intervention to help alleviate symptoms.

Pulmonary rehabilitation (PR) and cardiac rehabilitation (CR) are widely provided as they are proven interventions ${ }^{67}$ recommended for both patients with cardiac and pulmonary disease improving quality of life, exercise capacity and skeletal muscle function, increasing physical activity as well as causing central desensitisation to dyspnoea. Both forms of rehabilitation can also have an impact on reducing hospital admissions. ${ }^{8-11}$

Pulmonary rehabilitation is designed primarily for older individuals with chronic respiratory disease (such as COPD). The CR population is more diverse, ranging from secondary prevention in post myocardial infarction and cardiothoracic surgery patients to older individuals with CHF. Those with CHF are poorly represented in CR programmes despite strong evidence of effectiveness. Individuals with chronic respiratory disease (CRD) and CHF experience very similar symptoms and level of disability. Logic would therefore suggest that combined rehabilitation would be plausible and effective and breathlessness rehabilitation (BR) potentially brings together both diagnostic groups. These interventions are usually delivered as separate disease-specific programmes however their components are largely the same, both treating the primary symptom of breathlessness. Additionally, patients quite often have combined disease and share risk factors for other long-term conditions. ${ }^{112}$

A previous study investigating the feasibility and effectiveness of integrating patients with $\mathrm{CHF}$ and into a COPD PR programme, without comorbid disease, using the model of PR, ${ }^{13}$ reported that patients with CHF who underwent exercise rehabilitation improved similarly in their exercise performance and health status to those with COPD. This suggested service provision could be targeted around common disability rather than the primary organ disease. More recently a group of clinical experts and patients confirmed the logic and durability of this model ${ }^{14}$ concluding that existing pulmonary and cardiac services should be able to provide a flexible service that accommodates patients with both COPD and CHF. It was suggested the collaboration of work forces was feasible although acknowledging the services were frequently provided by discreet clinical teams with no overarching management and increase capacity for services. It was proposed that these services should be symptom focused rather than disease based. Exercise training was felt to be a core component but also any intervention should address dyspnoea management, psychological and education components as well.

Our aim was to describe and evaluate the effectiveness of a service development for BR which integrated individuals with both respiratory and/or cardiac diseases into one programme. We also explored the staff experiences on delivering the programme.

\section{METHODS}

\section{Service development}

A review of health and social care in Leicester, Leicestershire and Rutland, UK, created opportunities to improve care by redesigning a system around the future needs of patients in a sustainable way which was needed due to the rise in the number of people living with long-term and complex conditions. In 2014, a 5-year strategic plan was set out which identified long-term conditions, including patients with respiratory disease and heart failure as an area for integrating care. For this to happen, it would mean joining up services and workforces and encouraging staff to work differently to meet the needs of the changing population. The framework used within the trust to enable this transformation and sustainable change in culture and ways of working to happen was Listening into Action(Copyright Optimise, 2021; Milton Keynes, UK) which is a comprehensive, outcome-oriented approach to engage all the right people behind quality outcomes. It provides a comprehensive and joined-up way to tackle improvements in specific service areas, delivered through the direct engagement of the people who work there.

\section{Service reconfiguration}

Staff from both CR and PR teams were involved in the process mapping of both services to identify commonalities and differences in service provision, paperwork and data management. Peer working was encouraged between the services to provide an appreciation of the individual services. External funding from Education for Health enabled accredited staff training to be provided for each of the teams on disease pathology and management in either Cardiovascular Disease or Essentials of COPD before the BR classes commenced. There were also in-service training sessions on $\mathrm{CR} / \mathrm{PR}$ from the respective team for the other members of staff. Any other opportunities to attend training sessions in house on the respective topic were encouraged.

\section{Design}

This was a prospective mixed-methods service evaluation from between September 2017 and May 2019.

\section{Ethics}

Ethical approval was not required as the project was deemed to be audit. Consent was collected from participants as part of the routine clinical service.

\section{Patient and public involvement}

The initial idea for the project was presented to the department's Patient and public involvement (PPI) group (comprising of both cardiac and respiratory patients) some years ago with no preconceived plans of how this question might be addressed. There was support for the concept and an enthusiasm to be involved in the 
development of the service. As the project evolved, the PPI group was continually involved and guidance seeked as and when there was new information. Two of the PPI group members attended the steering group for the duration of data collection and dissemination of the project.

\section{Revised programme structure \\ Participants}

Patients were referred into $\mathrm{CR}$ and $\mathrm{PR}$ as normal by consultants, community heart failure nurses, specialist nurses, allied health professionals and general practitioners.

\section{Eligibility criteria}

Cardiac patients

Patients had a known diagnosis of heart failure (HF) (confirmed by echocardiogram ejection fraction (EF) $<40 \%$ ) or HF with a normal ejection fraction (normal EF, New York Heart Association (NYHA) 2 or more, 3 or more admissions over 12 months, self-reported symptoms on activity).

\section{Pulmonary patients}

Patients were eligible to partake if they had a confirmed diagnosis of a chronic respiratory disease (Medical Research Council (MRC)Dyspnoea Scale ${ }^{15} 2$ and above).

Patients were excluded by either service if:

- They had a lack of motivation (declined face-to-face classes) to participate in the programme,

- Had severe musculoskeletal or neurological disorders that limited mobility; patients needed to be independently mobile with or without a walking aid,

- Had a severe psychiatric disorder,

- Had a cardiac event within the last 6 weeks or

- Had a history of falls.

\section{Assessment}

All patients referred to either the PR or CR services were scheduled a comprehensive one-to-one assessment with a member of the multidisciplinary team (MDT). These are registered healthcare professionals who are clinical specialists in either PR or CR. The assessment included a review of the patient's relevant medical and social history, as well as an assessment of their current level of exercise performance and health status. Local risk stratification protocols were adhered to with telemetry performed on those cardiac patients at risk of exercise-induced arrhythmias or hypotension.

Patient assessment was carried out using a diseasespecific proforma individual to the services but collecting commonalities. Class paperwork was an amalgamation of the two services using the PR exercise diary for patients to record their progress in class and at home and the CR paperwork which was adapted to record patient observations, class attendance and exercises during class.
Setting

Patients attended a redesigned two times a week, groupbased, tailored exercise and education programme for 6 weeks, delivered by CR and PR staff. Each session lasted 2 hours which was divided into an hour for exercise training and an hour for an education session. The BR was delivered at one of two sites in Leicestershire, UK: acute hospital or community setting. Each class had between 8-12 participants in a group depending on the site capacity.

\section{Class structure-exercise modifications}

Prior to the BR class starting, resting blood pressure (BP), heart rate (HR) on all patients and capillary blood glucose levels in patients with diabetes were performed. Polar watches to monitor heart rate were provided to those cardiac patients deemed at risk of exercise-induced complications. Oxygen saturations were monitored in those patients whose desaturation was a concern following their initial assessment. A warm-up of 10-15 min was used in line with national recommendations for HF exercise programmes. ${ }^{16}$

The classes included both aerobic and resistance exercises. In order to try and incorporate both service guidelines, the exercises were split into two circuits: aerobic and strength. The aerobic component was based on individually prescribed walking from the incremental shuttle walking test (ISWT) ${ }^{17} 18$ and endurance shuttle walking test $(\mathrm{ESWT})^{19}$ performed at baseline. Walking time was progressed maintaining a Borg dyspnoea score ${ }^{20}$ of between 3 and 5 with the aim of walking for $10 \mathrm{~min}$ continuously initially. Static cycling was also completed, if the patient was able to, starting at 5 min but this could be increased to $10 \mathrm{~min}$ if tolerated or if this was preferable to walking. The intensity was prescribed based on the patient's breathlessness and perceived exertion symptom scores. Strength training consisted of both upper (bicep curls and triceps pull ups) and lower (sit to stand and step ups) limb resistance training with dumbbells which was based on 1 repetition maximum. Progression was achieved by maintaining a Borg perceived exertion $^{21}$ rating of $13-15$. Patients were encouraged to also complete a home exercise programme comprising of daily walking and one further strength session on the days when they did not attend rehabilitation classes. Home programmes were reviewed at each session to facilitate progress and influence changes in exercise behaviour beyond the supervised programme. Following completion of both the aerobic and resistance training, a cool down was performed.

\section{Class structure-education modifications}

There was an overarching generic education programme alongside disease-specific components. Generic topics included diet, exercise, coping with breathlessness, target setting and managing anxiety with the disease-specific topics incorporating medications, symptom control/ 
managing exacerbations and disease education. The education sessions were based on those provided by both teams in the traditional PR and CR classes, determining commonalities and adjusting the sessions for relevance as a generic group. They were delivered by a member of either the PR or CR team for the generic topics. For those disease-specific topics, a member of each team delivered the education to the appropriate subset of patients.

\section{Staffing}

All BR classes had a minimum of three members of staff (two registered and one assistant practitioner) during the exercise session, and where possible, one member of staff from each of the rehabilitation teams (one CR and one PR). Qualified members of the MDT included nurses, physiotherapists and occupational therapists with at least 5 years experience in delivering rehabilitation in their specialty

\section{Data collection}

\section{Clinical outcomes}

Process mapping identified the generic clinical outcomes used by both the PR and CR teams. These were not exhaustive due to the need for national data collection (NACR (National Audit for Cardiac Rehabilitation) and the RCP NACAP PR audit (Royal College of Physicians National Asthma and COPD Audit Programme) by the individual teams.

Generic clinical outcome measures were performed at baseline and repeated at the discharge assessment following completion of the 6-week BR programme. Maximal exercise capacity (ISWT) ${ }^{17}$; endurance exercise capacity $(\mathrm{ESWT})^{19}$; dyspnoea (chronic respiratory questionnaire - self reported - dyspnoea domain ${ }^{22} /$ chronic heart questionnaire - self reported - dyspnoea domain (CRQ-SR-D/CHQ-SR-D) $)^{23}$; anxiety and depression (Hospital Anxiety and Depression Scale (HADS) $)^{24}$; and muscle strength (quadriceps maximal voluntary contraction (QMVC)) were all collected. The Dartmouth COOP questionnaire was also used to assess generic functional status. ${ }^{25}$ Each question is a single-item measurement of an aspect of functional status. It provides an indicator of functional status, and the scores are ordinal and therefore presented as frequencies per response domain. Higher scores are indicative of a worse health-related quality of life.

Patients were classed as a completer if they achieved $75 \%$ of the programme $(8 / 12$ classes $)$ which is standard in clinical practice for those attending both traditional PR and CR classes.

\section{Statistics}

This was a pragmatic service evaluation. Analysis was primarily descriptive, that is, proportions and estimation of means and SD. A paired t-test was used to compare within-group changes in clinical outcomes with between group changes compared using an independent t-test and $\chi^{2}$ test. Data were analysed using the Statistical Package for the Social Sciences V.18 (SPSS).

\section{Qualitative outcomes}

A focus group methodology was chosen to enable discussions to emerge between participants that were less artificial than one-to-one semi-structured interviews. ${ }^{26}$ Seven staff who were regularly involved in delivering the BR programme were invited to attend one of two focus groups which took place in October/November 2018. Focus groups were conducted by three research associates working in the Centre for Exercise and Rehabilitation Science team, all with experience in qualitative methods. The first one research associate (AS) acted as the main facilitator, asking the questions and 'steering' the discussion. The other two facilitators (ED and SC) observed, took notes and prompted group members on any discussions that needed further explanation in one focus group each. The focus group schedule was developed in conjunction with the MDT and devised based on relevant literature and experience of the team. The semistructured topic guide included open questions which aimed to identify barriers and facilitators to delivering this new rehabilitation programme, staff feelings about working together, staff confidence in managing patients outside their usual specialty and explore staff training needs (see online supplemental box S1). Each focus group was audio-recorded and lasted approximately 1 hour.

\section{Qualitative data analysis}

Data were transcribed verbatim by a professional transcription service and analysed using thematic analysis. ${ }^{27}$ This approach follows six distinct stages: familiarisation with data; generating initial codes; searching for themes; reviewing themes; defining and naming themes and producing the report.

AS carried out initial coding and four other members of the team coded at least one transcript each to ensure validity and consistency, and to enhance interpretive authenticity (LH-W, MO, ED and SC). In addition, AS and LH-W discussed coding and theme decisions throughout data analysis, and other research team members met regularly to review emerging themes, and to search for and collate participant views.

\section{RESULTS}

\section{Service development}

After 18 months of integrated planning and education, the service was commenced by reallocating both standard PR and CR sessions to the novel breathlessness based programme. Once the programme had commenced, there have been minor adjustments to the service and continued in-service training. 
Table 1 Baseline characteristics

\begin{tabular}{|c|c|c|c|}
\hline & \multicolumn{2}{|l|}{$\begin{array}{l}\text { Whole group } \\
\mathrm{n}=272\end{array}$} & \multirow{2}{*}{$\begin{array}{l}\text { BR completers } \\
n=164\end{array}$} \\
\hline & CRD $n=193$ & CHF $\mathrm{n}=79$ & \\
\hline Gender (male:female) & $99: 94$ & $54: 25$ & 86: 78 \\
\hline Age (years) & $68.02 \pm 12.3$ & $70.6 \pm 13.4$ & $70.25 \pm 10.6$ \\
\hline Body mass index $\left(\mathrm{kg} / \mathrm{m}^{2}\right)$ & $28.7 \pm 7.8$ & $29.1 \pm 6.1$ & $28.88 \pm 7.3$ \\
\hline MRC dyspnoea grade (IQR) & $3(2-4)$ & - & $3(2-4)$ \\
\hline NYHA classification of heart failure (IQR) & - & $2(2-3)$ & $2(2-3)$ \\
\hline Pre ISWT (m) & $212.3(140.2)$ & $210.2(126.1)$ & $225.6(134.3)$ \\
\hline Pre ESWT (s) & $186.7(122.4)$ & $237.7(211.6)$ & $209.7(142.8)$ \\
\hline Pre QMVC (kg) & $21.6(10.7)$ & $20.8(7.7)$ & $21.8(10.1)$ \\
\hline Pre HADS - anxiety & $7.5(4.4)$ & $6.8(4.3)$ & $7.3(4.3)$ \\
\hline Pre HADS - depression & $6.6(3.7)$ & $6.2(3.4)$ & $6.6(3.6)$ \\
\hline Pre $C R Q / C H Q-S R-D$ & $2.1(1.4)$ & $4.0(1.4)^{\star}$ & $2.2(1.5)$ \\
\hline
\end{tabular}

${ }^{* *} \mathrm{p}<0.05$.

.BMI, body mass index; BR, breathlessness rehabilitation; CHF, chronic heart failure; CRD, chronic respiratory disease; $C R Q / C H Q-S R-D$, Chronic Respiratory Disease Questionnaire/Chronic Heart Disease Questionnaire - Self Report - Dyspnoea; ESWT, endurance shuttle walking test; HADS-A, Hospital Anxiety and Depression Score - anxiety; HADS-D, Hospital Anxiety and Depression Score - depression; ISWT, incremental shuttle walking test; kg, kilograms; kg/m², kilogram per metre squared; m, metres; MRC, Medical Research Council; $\mathrm{NYH}$, New York Heart Association; QMVC, quadriceps maximal voluntary contraction.;

\section{Clinical outcomes}

Two hundred and seventy-two patients ( $\mathrm{n}=193$ CRD (COPD 126; asthma 15; Interstitial Lung Disease (ILD) 21; bronchiectasis 11; other 20) ; $\mathrm{n}=79 \mathrm{CHF}$ (HF 36; HF with preserved ejection fraction (HFpEF) 20; HF with reduced ejection fraction 3; Myocardial Infarction (MI) 18; other 2)) were assessed and enrolled into BR. The cause of CHF was ischaemic in 46 patients versus 33 nonischaemic; only 2 patients had an ICD in situ. Baseline characteristics of the completers are described in table 1. Those that dropped out of the programme were significantly younger, had a lower exercise capacity and were less breathless.

One hundred and sixty-four patients $(60 \%)$ completed the programme ( $\mathrm{n}=127$ CRD $(66 \%) ; \mathrm{n}=37 \mathrm{CHF}(47 \%))$, with a statistically significant difference in dropout rates between pulmonary and cardiac (34 vs 53\%, p $\leq 0.05$ ) patients. The outcomes for the completers are outlined in table 2. All measures except HADS - depression and chronic respiratory questionnaire (CRQ)/chronic heart questionnaire $(\mathrm{CHQ})$ - dyspnoea showed changes that were clinically significant exceeding the MCID (minimal clinically important difference) following rehabilitation, where available from the literature. In context, MCID for ISWT in COPD $=40 \mathrm{~m}^{28}$ and in $\mathrm{HF}=42 \mathrm{~m}^{29}$; MCID for ESWT in COPD=between 174-279 $\mathrm{s}^{30}$; MCID for CRQ $\mathrm{CHQ}=0.5^{31}$ and MCID for HADS $=-1.5 .^{32}$

Statistically significant improvements $(\mathrm{p} \leq 0.0001)$ were seen in exercise capacity (mean change $(95 \% \mathrm{CI})$ : ISWT: $47.4 \mathrm{~m}$ (35.3 to 59.5); ESWT: $310.7 \mathrm{~s}$ (249.4 to 371.9$)$ ) and quadriceps strength (mean change (95\% CI): QMVC: 3.7 $\mathrm{kg}(2.3$ to 5.2)). Quality of life measures (mean change (95\% CI): CRQ/CHQ - dyspnoea: $0.4(0.1$ to 0.6$)$ ) and a reduction in the HADS (mean change $(95 \% \mathrm{CI})$ : HADS-A: -1.6 (-2.1 to -1.1$)$; HADS-D: -1.3 ( -1.7 to $-0.8)$ ) also showed a statistically significant improvement $(\mathrm{p} \leq 0.0001)$. Subgroup analysis showed significant within group changes $(p \leq 0.005)$ for outcome measures except the $\mathrm{CRQ} / \mathrm{CHQ}$ - dyspnoea in patients with CHF; however, there were no significant between group differences.

Frequency analysis performed on the COOP showed improvements in six out of the nine categories; no change was seen in social support, social activities and feelings which patients scored as 1 (no impairment) (table 3).

No adverse events were reported during the time period of the service evaluation.

\section{Qualitative results}

Qualitative focus groups took place 1 year after the new BR programme had commenced. Seven staff members took part (six women): one occupational therapist, three physiotherapists, one nurse and two assistant practitioners. The overarching theme identified from the analysis was evolving perceptions with three emerging main themes (collaboration and integration, service quality and future challenges) and nine subthemes. Online supplemental table S2 in the online supplement describes the findings in detail (see Qualitative Themes and Sub Themes findings Table) and also contains exemplar quotes.

\section{DISCUSSION}

More often than not patients with COPD have at least one other chronic health condition which will have implications for outcomes. ${ }^{33}$ It is reported that of those patients referred to PR, between $51 \%$ and $96 \%$ have 


\begin{tabular}{|c|c|c|}
\hline Dartmouth COOP domains* & $\begin{array}{l}\text { Pre } \\
n=40\end{array}$ & $\begin{array}{l}\text { Post } \\
n=40\end{array}$ \\
\hline Physical fitness & 4 & 3 \\
\hline Feelings & 1 & 1 \\
\hline Daily activities & 3 & 2 \\
\hline Social activities & 1 & 1 \\
\hline Pain & 4 & 3 \\
\hline Change in health & 3 & $1-2$ \\
\hline Overall health & 4 & 3 \\
\hline Social support & 1 & 1 \\
\hline Quality of life & 3 & 2 \\
\hline
\end{tabular}

All values are frequencies per response category.

*Higher scores in COOP (range 1-5) indicate worse health-related quality of life.

at least one coexisting condition. ${ }^{12}$ The best care for these patients with multimorbidity is to provide patientcentred care rather than disease specific. PR and CR are widely established effective models of care. Previous research has shown that exercise training programmes improve exercise capacity in and health-related quality of life in both disease groups. ${ }^{684}$ In a recent consensus, $87 \%$ of stakeholders thought that patients with CHF could exercise using COPD training principles and vice versa. ${ }^{14}$ The British Heart Foundation (a large charitable organisation supporting cardiac patients) published a report 'Turning back the tide on heart and circulatory diseases ${ }^{35}$ which encourages reimagining rehabilitation services and to explore more joined up models of BR. Within the National Health Service (NHS) long-term plan for England (2019), ${ }^{36}$ it is recognised that generic cardiac and pulmonary programmes have been shown to be effective for single index conditions and that this provides an opportunity to manage the groups collaboratively enabling more patients to access a programme. This is a novel description of a service redevelopment and evaluation of BR for those with CRD and CHF. We have demonstrated that combining expertise from staff with clinical expertise in CR and PR is possible. However, this required considerable service redesign, staff and patient engagement and workforce training. Overall though it was felt to be a positive experience; patients were happy to be in a combined class regardless of their condition and the staff learnt from each other, sharing specialist skills and knowledge, strengthening their skill set.

Following a consensus event which reviewed the current evidence surrounding outcome measures in PR and CR, health-related quality of life, exercise capacity and symptom evaluation were voted as the most important categories to assess for clinical purposes. ${ }^{37}$ Overall, this data indicate that a BR programme is effective at improving generic outcomes for participants regardless of their primary diagnosis. However, although the symptom of breathlessness improved statistically 
within the group it did not meet the MCID and therefore may not be clinically relevant. Patients had positive outcomes in both exercise capacity and health-related quality of life that were both statistically and clinically relevant as well as reflective of our traditional PR service and UK national audit data. ${ }^{38} 39$ Compared with the study by Evans $e t a l,{ }^{13}$ the cardiac group made similar improvements in exercise capacity and quality of life scores. Due to our inclusion criteria for the BR programme, patients with differing respiratory conditions not just COPD were included which may have accounted for smaller improvements in outcomes. Pilot data from the REHAB-HF study $(2017)^{40}$ suggested exercise capacity improved following rehabilitation. However, these changes, although similar to this study, were seen after a 12-week programme which started while patients were in hospital.

The Dartmouth COOP has been shown to be valid and responsive in patients with $\mathrm{COPD}^{41}$ and it is simple, reliable, quick and easy to perform and score. Improvements in this cohort were seen in the domains relating to physical fitness, daily activities, pain and quality of life, all of which are known to improve with PR and CR using other outcome measures. This suggests that patients are engaging with self-management of their conditions in order to gain these benefits.

Quality standards and audits helped inform joining of the two services. When initially looking at the design of the service, staff were mindful of incorporating outcomes that both services needed to report nationally and where possible commonalities that would enable reporting and evaluating the service possible.

BR has also allowed for the implementation of joint CR and PR services, using the clinical skills and knowledge of staff effectively, which in turn has benefitted patients who attend. As a result of this, there has been an increase in the number of cohorts provided, increasing capacity and patient choice. This also helps to meet the expectations of the NHS long-term plan. There were initial reservations by staff (as outlined in the focus groups) but following regular meetings of the teams to review both service practices and paperwork, it became apparent that there were more commonalities than first thought. However, this programme is unique to the UK healthcare system and may not be feasible in other countries due to the structure and eligibility criteria for attending a rehabilitation programme. This programme has enabled both services to be able to offer more choice to patients and integrate working with community rehabilitation teams with a commissioning model in place. Other longterm conditions may benefit (outside of pulmonary and cardiac conditions) from the programme, but this would require further evaluation.

In both COPD and CHF studies ${ }^{42-44}$ comparing centrebased or hospital-based versus a home-based setting, no significant differences were found between the two settings. One of the BR classes was held at a non-acute hospital setting and recruited lower risk patients. Those patients that tended to be more complex and sicker were advised to attend at the hospital-based BR class. Polar monitors were worn by patients that were identified as potentially presenting with exercise-induced complications otherwise it was felt $\mathrm{HR}$ and $\mathrm{BP}$ checks prior to commencing each exercise class was sufficient for monitoring the stability of the patients.

Although there were a higher proportion of dropouts in the CHF group, documentation did not show a trend or particular reason to account for this. Reasons given were typical to those described by patients dropping out from traditional rehabilitation programmes for example, transport, family commitments, comorbidities. The programme was designed for older patients with HF and therefore there may have been a bias towards those with HFpEF who historically are older patients. This may have contributed to the high number of dropouts in this group also. A limitation to the study, is there was no control group; this was due to it being a service reconfiguration and evaluation. However, compared with traditional PR classes, similar outcomes were found. If time had allowed, further qualitative analysis of the patients' experience would have provided useful information to inform future developments of the service and quality improvement.

Due to there being general similarities in core topics of the educational component, it made delivery of the majority of the education to both cardiac and respiratory patients feasible while tailoring some of the diseasespecific information.

For BR rehabilitation to be truly generic, the intervention needs to be patient focused which includes an intervention to address exercise capacity and also dyspnoea, psychological and educational needs of patients and carers.

\section{CONCLUSION}

We anticipate that this model may be feasible to grow with the provision of generic rehabilitation to other chronic conditions whose core complaint is breathlessness. Being able to see more patients with fewer resources in a combined programme will increase capacity in the separate disease-specific classes for patients with more complex needs. Given the significance of comorbid disease it is an approach that warrants further consideration.

Author affiliations

${ }^{1}$ Centre for Exercise and Rehabilitation Science, Pulmonary Rehabilitation Department, University Hospitals of Leicester NHS Trust, Leicester, UK ${ }^{2}$ Department of Respiratory Sciences, University of Leicester, Leicester, UK ${ }^{3}$ School of Psychological, Social and Behavioural Sciences, Coventry University Faculty of Health and Life Sciences, Coventry, UK

Acknowledgements This service evaluation was funded by the National Institute for Health Research (NIHR) Collaboration for Leadership in Applied Health Research and Care in the East Midlands (CLAHRC-EM) and took place at the University Hospitals of Leicester NHS Trust and the National Centre for Sports and Exercise Medicine at Loughborough University. Support was provided by the NIHR Leicester Biomedical Research Centre (BRC) - Respiratory. The views expressed are those of the author, not necessarily those of the NHS, NIHR or the Department of Health. 
The authors wish to acknowledge both the Cardiac and Pulmonary Rehabilitation Departments within the University Hospitals of Leicester NHS trust, Leicester. They would also like to thank Stacey Chantrell and Mark Orme (research associates) for their help with the qualitative focus groups.

Contributors All authors contributed to the writing of the paper. EC (guarantor), SW, ED, NG, LH-W and AW were involved in the design and intervention work. EC and LH-W analysed and interpreted the data. AS (a research associate working in a respiratory setting, trained in qualitative methods) conducted both focus groups and ED (coauthor and research physiotherapist) took notes in one focus group, both helped with agreeing the qualitative themes along with CB. EC, LH-W and SS have been involved in drafting the work or revising it critically for important intellectual content and have given the final approval of the version published.

Funding This service evaluation was funded by the National Institute for Health Research (NIHR) Collaboration for Leadership in Applied Health Research and Care in the East Midlands (CLAHRC-EM). The role of the funder did not involve the study design, collection, management, analysis and interpretation of the data, writing and submission of the report.

Competing interests None declared.

Patient consent for publication Not applicable.

Provenance and peer review Not commissioned; externally peer reviewed.

Data availability statement Data are available upon reasonable request.

Supplemental material This content has been supplied by the author(s). It has not been vetted by BMJ Publishing Group Limited (BMJ) and may not have been peer-reviewed. Any opinions or recommendations discussed are solely those of the author(s) and are not endorsed by BMJ. BMJ disclaims all liability and responsibility arising from any reliance placed on the content. Where the content includes any translated material, BMJ does not warrant the accuracy and reliability of the translations (including but not limited to local regulations, clinical guidelines, terminology, drug names and drug dosages), and is not responsible for any error and/or omissions arising from translation and adaptation or otherwise.

Open access This is an open access article distributed in accordance with the Creative Commons Attribution Non Commercial (CC BY-NC 4.0) license, which permits others to distribute, remix, adapt, build upon this work non-commercially, and license their derivative works on different terms, provided the original work is properly cited, appropriate credit is given, any changes made indicated, and the use is non-commercial. See: http://creativecommons.org/licenses/by-nc/4.0/.

ORCID iD

Emma Chaplin http://orcid.org/0000-0003-0981-2980

\section{REFERENCES}

1 Crisafulli E, Costi S, Luppi F, et al. Role of comorbidities in a cohort of patients with COPD undergoing pulmonary rehabilitation. Thorax 2008;63:487-92.

2 Doherty P. The national audit of cardiac rehabilitation : annual statistical report. London: British Heart Foundation, 2017.

3 Gosker HR, Wouters EFM, van der Vusse GJ, et al. Skeletal muscle dysfunction in chronic obstructive pulmonary disease and chronic heart failure: underlying mechanisms and therapy perspectives. Am J Clin Nutr 2000;71:1033-47.

4 NICE. CG101: chronic obstructive pulmonary disease in over 16S: diagnosis and management, 2010. Available: https//www.nice.org. uk/guidance/cg101

5 NICE. Myocardial infarction: cardiac rehabilitation and prevention of further cardiovascular disease, 2014. Available: https://www.nice. org.uk/guidance/cg172

6 McCarthy B, Casey D, Devane D, et al. Pulmonary rehabilitation for chronic obstructive pulmonary disease. Cochrane Database Syst Rev 2015:CD003793.

7 Taylor RS, Long L, Mordi IR, et al. Exercise-Based Rehabilitation for Heart Failure: Cochrane Systematic Review, Meta-Analysis, and Trial Sequential Analysis. JACC Heart Fail 2019;7:691-705.

8 Sagar VA, Davies EJ, Briscoe S, et al. Exercise-based rehabilitation for heart failure: systematic review and meta-analysis. Open Heart 2015;2:e000163.

9 Seymour JM, Moore L, Jolley CJ, et al. Outpatient pulmonary rehabilitation following acute exacerbations of COPD. Thorax 2010;65:423-8.

10 Eaton T, Young P, Fergusson W, et al. Does early pulmonary rehabilitation reduce acute health-care utilization in COPD patients admitted with an exacerbation? a randomized controlled study. Respirology 2009;14:230-8.
11 Revitt O, Sewell L, Morgan MDL, et al. Short outpatient pulmonary rehabilitation programme reduces readmission following a hospitalization for an exacerbation of chronic obstructive pulmonary disease. Respirology 2013;18:n/a-8.

12 Franssen FME, Rochester CL. Comorbidities in patients with COPD and pulmonary rehabilitation: do they matter? European Respiratory Review 2014;23:131-41.

13 Evans RA, Singh SJ, Collier R, et al. Generic, symptom based, exercise rehabilitation; integrating patients with COPD and heart failure. Respir Med 2010;104:1473-81.

14 Man WD-C, Chowdhury F, Taylor RS, et al. Building consensus for provision of breathlessness rehabilitation for patients with chronic obstructive pulmonary disease and chronic heart failure. Chron Respir Dis 2016;13:229-39.

15 Fletcher C. Standardised questionnaire on respiratory symptoms. $\mathrm{Br}$ Med J 1960;2:1665 https://www.ncbi.nlm.nih.gov/labs/pmc/articles/ PMC2098438/

16 Association of Chartered Physiotherapists in Cardiac Rehabilitation (ACPICR). ACPICR standards for physical activity and exercise in the cardiac population, 2015. Available: http://acpicr.com/ publications

17 Singh SJ, Morgan MD, Scott S, et al. Development of a shuttle walking test of disability in patients with chronic airways obstruction. Thorax 1992;47:1019-24.

18 Monteiro DP, Brito RR, Carvalho MLV, et al. Shuttle walk test as an instrument for assessing functional capacity: a literature review. Revista Ciência \& Saúde 2014;7:92-7.

19 Revill SM, Morgan MDL, Singh SJ, et al. The endurance shuttle walk: a new field test for the assessment of endurance capacity in chronic obstructive pulmonary disease. Thorax 1999;54:213-22.

20 Burdon JG, Juniper EF, Killian KJ, et al. The perception of breathlessness in asthma. Am Rev Respir Dis 1982;126:825-8.

21 Borg G. Perceived exertion as an indicator of somatic stress. Scand $J$ Rehabil Med 1970;2:92-8.

22 Williams JEA, Singh S, Sewell L. Development of a self-reported chronic respiratory questionnaire (CRQ-SR). Thorax 2001;56:954-9.

23 Evans RA, Singh SJ, Williams JE, et al. The development of a selfreported version of the chronic heart questionnaire. J Cardiopulm Rehabil Prev 2011;31:365-72.

24 Zigmond AS, Snaith RP. The hospital anxiety and depression scale. Acta Psychiatr Scand 1983;67:361-70.

25 Eaton T, Young P, Fergusson W, et al. The Dartmouth coop charts: a simple, reliable, valid and responsive quality of life tool for chronic obstructive pulmonary disease. Quality of Life Research 2005;14:575-85.

26 Willig C. Introducing qualitative research in psychology. 2 Edn. McGraw Hill, Open University Press, 2008.

27 Braun V, Clarke V. Using thematic analysis in psychology. Qual Res Psychol 2006;3:77-101.

28 Evans RA, Singh SJ. Minimum important difference of the incremental shuttle walk test distance in patients with COPD. Thorax 2019;74:994-5.

29 Houchen-Wolloff L, Boyce S, Singh S. The minimum clinically important improvement in the incremental shuttle walk test following cardiac rehabilitation. Eur J Prev Cardiol 2015;22:972-8.

30 Zatloukal J, Ward S, Houchen-Wolloff L, et al. The minimal important difference for the endurance shuttle walk test in individuals with chronic obstructive pulmonary disease following a course of pulmonary rehabilitation. Chron Respir Dis 2019;16:147997311985382-7.

31 Redelmeier DA, Guyatt GH, Goldstein RS. Assessing the minimal important difference in symptoms: a comparison of two techniques. $J$ Clin Epidemiol 1996;49:1215-9.

32 Smid DE, Franssen FME, Houben-Wilke S, et al. Responsiveness and MCID estimates for cat, CCQ, and HADS in patients with COPD undergoing pulmonary rehabilitation: a prospective analysis. $J \mathrm{Am}$ Med Dir Assoc 2017;18:53-8.

33 Holland AE, Harrison SL, Brooks D. Multimorbidity, frailty and chronic obstructive pulmonary disease: are the challenges for pulmonary rehabilitation in the name? Chron Respir Dis 2016;13:372-82.

34 Dimopoulos S, Anastasiou-Nana M, Sakellariou D, et al. Effects of exercise rehabilitation program on heart rate recovery in patients with chronic heart failure. Eur J Cardiovasc Prev Rehabil 2006;13:67-73.

35 British Heart Foundation. Turning back the tide on heart and circulatory diseases 2019.

36 NHS England. The NHS long term plan, 2019. Available: https:// www.longtermplan.nhs.uk

37 Jones AV, Evans RA, Man WD-C, et al. Outcome measures in a combined exercise rehabilitation programme for adults with COPD 
and chronic heart failure: a preliminary stakeholder consensus event. Chron Respir Dis 2019;16:147997311986795-11.

38 British Heart Foundation. The National audit of cardiac rehabilitation: quality and outcomes report, 2019. Available: https://www.bhf.org uk/informationsupport/publications/statistics/national-audit-ofcardiac-rehabilitation-quality-and-outcomes-report-2019

39 Steiner M, McMillan V, Lowe D. Pulmonary rehabilitation: an exercise in improvement. National chronic obstructive pulmonary disease (COPD) audit programme: clinical and organisational audits of pulmonary rehabilitation services in England and Wales 2017. National report. London: RCP, 2018.

40 Reeves GR, Whellan DJ, O'Connor CM, et al. A novel rehabilitation intervention for older patients with acute decompensated heart failure: the rehab-hf pilot study. JACC Heart Fail 2017;5:359-66.
41 Eaton T, Young P, Fergusson W, et al. The Dartmouth coop charts: a simple, reliable, valid and responsive quality of life tool for chronic obstructive pulmonary disease. Qual Life Res 2005;14:575-85.

42 Waterhouse JC, Walters SJ, Oluboyede $\mathrm{Y}$, et al. A randomised $2 \mathrm{X} 2$ trial of community versus hospital pulmonary rehabilitation, followed by telephone or conventional follow-up. Health Technol Assess 2010;14:1-140.

43 Maltais François, Maltais F, et al. Effects of home-based pulmonary rehabilitation in patients with chronic obstructive pulmonary disease. Ann Intern Med 2008;149:869-78.

44 Taylor RS, Dalal H, Jolly K. Home-based versus centrebased cardiac rehabilitation. Cochrane Database Syst Rev 2015;8:CD007130. 